\title{
UMA NOVA GERAÇÃO DO INVESTIMENTO SOCIAL: ARRANJOS INSTITUCIONAIS PARA IMPACTO COLETIVO
}

\author{
Sergio Andrade
}

\section{// resumo}

A incorporação de tendências internacionais pelo campo do investimento social privado (ISP) no Brasil tem aproximado seus protagonistas de modalidades mais complexas de governança nas iniciativas que desenvolvem. Um maior nível de ambição em termos de impacto e escala, pressões financeiras e busca por efetividade têm levado ao aprofundamento da compreensão sobre impacto coletivo, conceito esboçado na Universidade de Stanford nos anos 2010. As características brasileiras reforçam a importância da atuação do ISP em causas estruturantes, em arranjos para o fortalecimento de políticas públicas envolvendo, principalmente, entes públicos locais, em colaboração direta ou em sinergia com organizações da sociedade civil. As experiências de impacto coletivo, embora ainda pouco numerosas no Brasil, surgem como alternativa na solução de problemas complexos dessa natureza, que pedem abordagem sistêmica, coordenação e cooperação entre organizações intersetoriais. Este texto aborda duas experiências que revelam o potencial desse modelo, baseado em avaliação e feedbacks contínuos para aprendizagem rápida e gestão adaptativa.

| palavras-chave: investimento social privado | impacto coletivo | arranjos institucionais políticas públicas. 


\section{artigos GIFE}

\section{OS ARTIGOS GIFE}

A série Artigos GIFE publica reflexões e análises de pesquisadores brasileiros de diferentes áreas do saber com o objetivo de estimular, ampliar e disseminar a produção de conhecimento qualificado sobre o campo da filantropia, do investimento social privado e da sociedade civil no Brasil.

A partir da premissa de que a produção de conhecimento sobre esses temas tem um papel fundamental na expansão, diversificação e qualificação da ação pública pela sociedade, a iniciativa também pretende contribuir para ampliar as conexões entre o setor, as universidades e os centros de pesquisa, promovendo e apoiando o envolvimento de novos atores com a temática e a circulação ampliada de ideias em torno dela.

Este texto integra a segunda edição dos Artigos GIFE, que propõe a publicação mensal de artigos selecionados por meio de chamada pública e convite a autores especialistas em temáticas específicas e relevantes para o setor, buscando apoiar e fomentar a produção de conhecimento sobre o investimento social no Brasil.

\section{O GIFE}

O Grupo de Institutos Fundações e Empresas (GIFE) é uma organização sem fins lucrativos que reúne associados de origem empresarial, familiar ou independente que investem em projetos de interesse público. Criado em 1989 como grupo de troca e colaboração e institucionalizado em 1995 por 25 organizações, tornou-se referência no campo da filantropia e do investimento social privado no Brasil.

Nesses mais de 20 anos de atuação, tem contribuído para o fortalecimento de práticas e ações a serviço do bem comum no país, trabalhando para expandir, qualificar e fortalecer o investimento social privado, diversificar e ampliar atores e recursos, criando referências e estimulando boas práticas de gestão, bem como articulando o setor com a sociedade e a agenda pública. Atualmente, o GIFE reúne mais de 150 associados que, somados, aportam mais de R\$ 3 bilhões por ano em projetos próprios e no apoio a projetos de terceiros. 


\section{INTRODUÇÃO}

Não faltam ditados sobre as virtudes de construções conjuntas. Escolha o seu! O fato é que soluções para problemas complexos dependem de cooperação e coordenação. Este paradigma está presente na administração, na ciência política e até no design. O investimento social privado (ISP) brasileiro sabe disso há muito tempo e tem usado modelos cada vez mais articulados entre governo, setor privado e sociedade civil. Essas iniciativas contrastam com projetos próprios autossuficientes, sem o envolvimento direto do setor público. Esse relativo consenso, evidenciado pelos últimos Censos GIFE, se estabeleceu pela constatação de que transformações sociais dependem de políticas públicas (GIFE, 2017, p. 203).

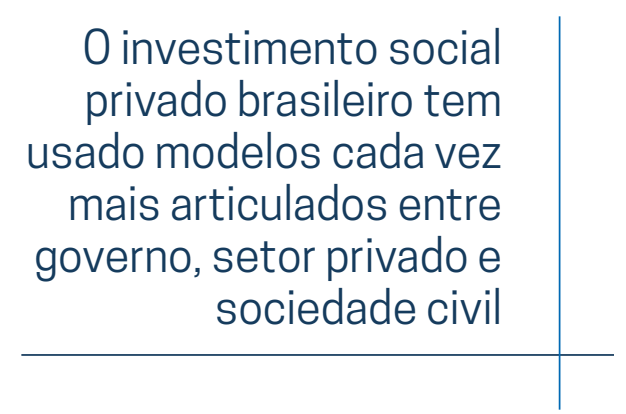

O impacto do ISP é mais relevante quando conjugado com dimensões estruturantes, características das políticas públicas. Quando a atuação não se limita aos efeitos imediatos de um problema, englobando também suas causas, de maneira integrada, o ISP também ganha mais legitimidade e escala, objetivos presentes nas estratégias contemporâneas dos principais investidores.

Neste artigo vamos explorar desdobramentos de modelos de ações estruturantes, analisando as possibilidades e os desafios de experiências de impacto coletivo para propor aprimoramentos nas formas de organização do trabalho conjunto entre investidores sociais, sociedade civil e, principalmente, com o setor público para a solução de problemas complexos. Na primeira parte do artigo, veremos um panorama sobre as mudanças na agenda pública com a aprovação da Lei 13.460/17, reconhecida como o Código de Defesa dos Usuários do serviço público, acompanhada de promissores movimentos de inovação, transparência e transformação digital em espaços de governo, analisando como podem se constituir em gatilhos para potencializar o impacto do ISP. Vamos conhecer, em seguida, pressupostos da abordagem de impacto coletivo para, em seguida, apresentar duas experiências brasileiras retratadas a partir da prática do autor. Por fim, considerações adicionais são feitas. 


\section{REINVENTAR OS SERVIÇOS PÚBLICOS: 0 QUE 0 ISP TEM A VER COM ISSO?}

Há muito tempo, virou lugar comum retratar a administração pública ou o Estado em cenas folclóricas de burocracia, corrupção e algum tipo de grosseria ou excentricidade por parte de algum funcionário mal pago. O imaginário coletivo vive povoado por imagens de longas filas, carimbos e papéis em excesso, pela figura de um leão faminto por impostos ou por algum tipo de figura obscena comandando desvios e ilegalidades. Os acontecimentos dos últimos anos não ajudaram, ao contrário. Quem poderia discordar, não é mesmo? Quem já não foi vítima de casos excêntricos envolvendo serviços públicos?

Na América Latina, a realidade pode ser tão caricata que virou tema de concurso na Bolívia (DASSEN, 2015), apoiado pelo Banco Interamericano de Desenvolvimento (BID), que reconhece o pior trâmite burocrático do país. Os casos vencedores dessa competição curiosa não são tão diferentes de situações que vemos no Brasil, onde idosos imobilizados em suas camas são arrastados por parentes até alguma repartição pública para dar "prova de vida" ou quando milhares de pessoas esperam por mais de 24 horas em uma fila em busca de emprego, competindo por um número significativamente menor de vagas para as quais, normalmente, não têm a qualificação necessária. Aliás, não é preciso procurar muito para se deparar com exemplos como esses aos montes.

Essa narrativa de ineficiência e incapacidade ganhou outras feições recentemente. A crise de credibilidade que tanto afetou a política institucional também fez outras vítimas. O Estado, as instituições, a administração pública e até mesmo o funcionalismo parecem figurar como os grandes problemas do Brasil. Essas explicações são demasiado simplistas. Ignoram transformações absolutamente vitais para o país e uma trajetória de desenvolvimento que transformou o aparelho do Estado e suas burocracias. Mesmo assim, precisamos reconhecer que há muito a fazer para alcançar padrões de qualidade satisfatórios na prestação de serviços públicos à população. Mas o que deve ser aperfeiçoado, exatamente? Que dimensões da prestação de serviços públicos são valorizadas pelos cidadãos, afinal?

Um estudo do BID, publicado no final de 2018 (ROSETH et al., 2018), afirma que a principal queixa dos usuários se refere à existência de barreiras ao acesso à informação e requisitos necessários nos trâmites administrativos. Deslocamentos para obter ou entregar documentações que, muitas vezes, já estão nas mãos da administração pública. Em seguida, pelo atendimento ao público realizado por funcionários desmotivados.

Se as queixas são contundentes, as reações também existem, gerando fortes respostas institucionais, no caso brasileiro verdadeiros movimentos pela transformação do serviço público, como a reforma gerencial de 1995 (BRESSER, 2000) ou os mais recentes movimentos em favor da inovação nos governos, capitaneados por redes, escolas, laboratórios e modelos de coprodução de soluções e uso de tecnologias (CAVALCANTE, 2017; 2019). E a roda continua a se movimentar.

Em 2017, o Brasil ganhou um novo marco legal sobre participação, proteção e defesa dos direitos dos usuários dos serviços públicos. A Lei 13.460/17, chamada de Código de Defesa dos Usuários, determinou a obrigatoriedade de avaliação periódica dos serviços prestados por todas as instituições públicas, incluindo União, estados e municípios, no âmbito dos três poderes. Posteriormente, o Decreto 9.094/17 tratou da simplificação do atendimento prestado aos usuários. Esses dispositivos legais induziram órgãos e entidades federais a se apropriarem das ferramentas de pesquisa de satisfação dos usuários, além de usar as informações coletadas nas ouvidorias para aprimorar os serviços públicos.

Não é muito comum a realização de extensas avaliações sobre a prestação de serviços públicos e é ainda menos comum que sejam conhecidas. O levantamento nacional realizado no final de 2018 pelo Ministério do Planejamento, Desenvolvimento e Gestão catalogou, pela primeira vez, dados de qualidade de cerca de 500 serviços prestados pela Administração Pública Federal. A pesquisa, chamada Gestão da Qualidade em Serviços Públicos Federais (INOVA, 2018), revelou o seguinte quadro a respeito das instituições federais:

- 69,9\% não possuem processo regular de avaliação da qualidade do serviço prestado;

- $84,9 \%$ não seguem um modelo de gestão da qualidade definido para a prestação do serviço;

- $61,2 \%$ não possuem uma ferramenta para que o usuário possa avaliar sua satisfação quanto ao serviço recebido; 
- o mais comum é exigir do usuário cinco documentos para atender solicitações;

- 50,5\% não medem o tempo de espera do usuário até a entrega do serviço;

- $81,0 \%$ afirmam utilizar dados de reclamações e sugestões para a melhoria do serviço e mais de $50 \%$ envolvem os usuários nesse processo.

Se essa é a realidade em nível federal, provavelmente estados e municípios de maneira geral têm um quadro ainda mais preocupante. Essa análise é particularmente importante para o nível subnacional. Nos municípios, podemos dizer que a compreensão do desempenho na prestação de serviços é uma espécie de proxy da performance da administração pública como um todo. Compreender dimensões de qualidade - como 1) tempo de espera, 2) relação custo-benefício, 3) relação com o usuário, 4) gestão de pessoas e atendimento e 5) digitalização nos permitiria, por exemplo, fazer inferências a respeito da eficiência, eficácia e efetividade da administração, bem como de sua relação com os cidadãos e, por conseguinte, da própria qualidade da democracia local.

Aprimorar a prestação de serviços, a oferta finalística e não apenas o desenho e a formulação da política pública, foco tradicional do ISP, significaria aperfeiçoar a administração pública como um todo, enfrentando seus dilemas mais conhecidos, como ausência de planejamento estratégico, fragmentação administrativa (feudos), burocracia, desconfiança e desconhecimento da experiência do cidadão.

Por que esses desafios são relevantes para investidores sociais privados? Há pelo menos duas dimensões que gostaríamos de considerar aqui. Inicialmente, é preciso ter claro que não é possível resolver problemas públicos complexos sem a atuação dos governos, então é necessário que eles assumam suas responsabilidades. Nenhuma boa literatura disponível vai relativizar a importância das instituições públicas para o desenvolvimento (ACEMOGLU e ROBINSON, 2012; EVANS, 1993; NORTH, 2018; RUTHERFORD, 1994). Assim, aprimorar desempenho e capacidade dos governos passa a ser uma condição necessária para chegar a impactos sociais aceitáveis ou a mudanças estruturantes, capazes de responder às ambições de investidores sociais buscando transformações sociais autênticas.

Se, pelo argumento institucional, trabalhar ou não com governos poderia parecer opção, os modelos mais aceitos para tratar problemas complexos (wicked problems) - ou seja, multicausais - reforçam essa necessidade ao enfatizar a importância de sinergias entre múltiplos atores e instituições de modo mais orgânico (BROWN, HARRIS e RUSSEL, 2010). A abordagem sistêmica pressupõe compreensão e respostas a um problema considerando a interdependência entre variáveis muito distintas, estabelecendo, assim, contrapontos a motivações, causas e soluções únicas e definidoras. Dito de outro modo, problemas complexos não são algo definitivo e estável, as circunstâncias também se modificam (legislação, evidências científicas, recursos, fatores políticos), não havendo, portanto, solução permanente. Por isso, enfrentar problemas complexos equivale a mirar em um alvo em movimento, no qual os próprios governos isoladamente não são capazes de acertar. Tampouco é possível que o setor privado ou a sociedade civil se encarreguem deles sem a participação pública.

Vale aqui lembrar da parábola do elefante e dos cegos, em que cada qual toca uma parte do animal imaginando se tratar de algo completamente distinto daquilo que define sua ontologia. Como nenhum deles conhece todas as faces do conjunto, ignoram tratar-se do animal que é. A compreensão e resposta aos problemas complexos têm dimensões análogas. Como oferecer educação adequada, modernizar a infraestrutura, gerar trabalho de qualidade, construir cidades mais humanas, manter o meio ambiente equilibrado e a população saudável? Quem deve agir? O que deve ser feito? Essas reflexões demonstram o quanto é importante assumir responsabilidades, ou melhor, corresponsabilidades. Os desafios são grandes demais. Não podemos mais apenas delegar exclusivamente aos governos atribuições que escapam à sua governabilidade e capacidade. Da mesma maneira, não podemos assumir protagonismo sobre algo que foge às competências e, principalmente, ao papel e ao mandato característico do ISP (ANDRADE, 2014; 2016). Precisamos colaborar e cooperar para construir soluções. Governos, empresas e sociedade civil devem agir de forma coordenada. Porém, como podemos fazer isso de uma maneira mais efetiva? Que práticas de governança podem trazer respostas satisfatórias? 


\section{IMPACTO COLETIVO: APRIMORANDO A SINERGIA ENTRE ISP E POLİTICAS PÜBLICAS}

As referências sobre impacto coletivo são relativamente novas no Brasil. Desde as primeiras produções e iniciativas, conduzidas no âmbito da Universidade de Stanford ou por meio do Collective Impact Forum (CIF, 2019), a abordagem vem ganhando relevância no mundo enquanto modelo de atuação aplicado a problemas complexos, quando soluções técnicas pré-determinadas e medidas isoladas, concorrentes ou fragmentadas, não são capazes de resolver. Pressupõe uma abordagem sistêmica do impacto social com enfoque na relação entre organizações de distintos setores, em que confiança, capacidade de coordenação, processos de avaliação, aprendizagem rápida e gestão adaptativa são decisivos para chegar aos resultados comuns esperados (HANLEYBROWN, KANIA e KRAMER, 2012).

Nessa abordagem mais orgânica, o que lembra em parte o princípio das metodologias ágeis, o desempenho é resultado de amadurecimentos a partir da prática, com tentativas e erros que levam aos "melhores resultados possíveis" nas circunstâncias e contextos existentes. Não há soluções definitivas e percursos lineares, características típicas do planejamento tradicional. Causas e efeitos importam e não há uma eliminação completa do problema.

O modelo de impacto coletivo requer fundamentalmente um processo de aprendizagem e interação entre as diversas organizações públicas e privadas participantes
O modelo de impacto coletivo, tal como preconizado pelo Collective Impact Forum (CIF, 2019), depende fortemente da colaboração e alinhamento de objetivos e metas. Requer fundamentalmente um processo de aprendizagem e interação entre as diversas organizações públicas e privadas participantes, combinando visão interdisciplinar e intersetorial. Desse modo, resolver problemas é aprender continuamente, são pessoas acertando e errando juntas. Por isso, pressupõe líderes comprometidos e proativos, uma liderança sistêmica, adaptativa, baseada na cultura de escuta e empatia. Para que funcione requer, além de uma agenda motivada, recursos suficientes por um prazo adequado ( 2 a 3 anos). Financiamentos de curto prazo, muitas vezes característicos do modelo atual de ISP, tendem a frustrar iniciativas baseadas nesse arranjo.

Tomando como exemplo, no investimento social para o desenvolvimento territorial essas pré-condições são muito fáceis de evidenciar, pois a construção de agendas estranhas aos atores no território, ou pensadas apenas por um pequeno grupo de instituições locais, costuma ter pouca legitimidade, levando a resultados limitados e pouco sustentáveis. $\mathrm{Na}$ mesma linha, investimentos por curtos períodos de tempo não são suficientes para construir bases de capacidades individuais e institucionais necessárias para que o território possa mudar uma realidade de forma estrutural.

De modo complementar, transformações sistêmicas também implicam em competências, habilidades e atitudes específicas. A capacidade de desafiar pressupostos, ouvir, exercitar empatia e manter-se flexível e resiliente são alguns desses atributos, muito presentes também nos modelos educacionais desenhados para formar os chamados profissionais do futuro. Nessas abordagens, o trabalho em equipe induz uma espécie de inteligência coletiva, um "modo cidadão" que permite perceber um amplo espectro de interesses envolvidos. São sujeitos e não apenas instituições, de modo que as afinidades e o convívio são importantes, uma combinação de abordagem relacional e racional.

Do ponto de vista da governança, além da visão transversal dos objetivos e de como alcançá-los, é necessário contar com legitimidade e engajamento dos atores críticos, aqueles que são parte do problema e também parte da solução. Combinações diferentes na composição dos atores certamente levam a resultados diferentes. A construção de uma agenda comum passa por um plano de ação com uma boa descrição do problema a ser combatido, incluindo dados, diferentes visões e narrativas. Como não poderia deixar de ser, o plano deve trazer ainda objetivos e estratégias claros para a mudança desejada, princípios que guiem o comportamento do grupo, com padrões de conduta e compliance, bem como mecanismos de avaliação, feedback e accountability. 
Considerando que a característica do processo de impacto coletivo é o aprendizado rápido, a partir de tentativas e erros das experiências em curso, um plano de ação bem desenhado é o que leva em conta uma boa delimitação geográfica do problema, assim como limites, possibilidades e aspirações dos atores locais envolvidos. Considerando a flexibilidade da abordagem, não foca nas atividades e sim na proposta mais geral de ação em direção ao objetivo comum, combinando conquistas de curto prazo (quick wins) e estratégias sistêmicas de longo prazo. Trata-se de um plano de ação mutável para refletir novas aprendizagens, mudanças no contexto local e a chegada de outros atores, com novos insights e prioridades.

Tão importante quanto o plano em si, que materializa a visão compartilhada, a literatura sobre o modelo (CIF, 2019) destaca ainda outros quatro requisitos para a implantação bem-sucedida de experiências de impacto coletivo. O primeiro é a existência de sistemas de mensuração compartilhados, cujos resultados de esforços a serem medidos sejam pactuados e o estabelecimento de rotinas para coleta e tratamento de dados seja acordado. Em segundo aparece a complementaridade e o reforço mútuo das habilidades e atividades de cada organização envolvida no arranjo, uma espécie de princípio de não-concorrência. O arranjo também deve prever uma comunicação contínua, baseada em um vocabulário comum e um fluxo constante de informações formais e informais (ambiente externo e interno). Isso inclui reuniões com agenda estruturada e presença de representantes com poder de decisão, além de espaços para troca de conhecimentos e aprendizados mútuos, sinergia e motivação. Por último, uma condição importante para implantação bem-sucedida de iniciativas de impacto coletivo é a existência de uma organização central de suporte, com equipe preparada para exercer funções de facilitação, planejamento, gerenciamento e amparo operacional (comunicação, administração, logística etc.), apoio na coleta e análise de dados, assim como atração de investimentos.

Os parágrafos acima permitiram compreender melhor, em termos metodológicos, a abordagem de impacto coletivo e seu potencial para inspirar e orientar experiências de investimento social alinhados a políticas públicas em dimensões como governança, modelagem do impacto, gestão de parcerias, formação de equipes, avaliação e coinvestimento. Vamos agora conhecer alguns repertórios possíveis dessa abordagem praticados por aqui.

\section{EXPRESSÕES BRASILEIRAS: GRAMÁTICAS DO IMPACTO COLETIVO NO BRASIL}

Aqui são descritas duas experiências que vêm buscando na abordagem do impacto coletivo referências para combinar interesses, recursos e atuações. Elas assumem uma assinatura muito pessoal, pois também constituem vivências que este autor tem experimentado nos últimos anos na busca de soluções para problemas públicos. De maneira alguma simbolizam o estado da arte da metodologia, mas iluminam muito bem seus potenciais e limites. Nelas é possível notar recortes específicos de princípios metodológicos do impacto coletivo.

Abordagem semelhante tem sido empregada, por exemplo, em uma experiência que vem ganhando destaque a partir da projeção dos resultados e de sua metodologia para solução de problemas complexos, tendo já alcançado várias regiões do país tratando de temas como mobilidade, integração de refugiados, dinamismo econômico, transparência, educação, agricultura e geração de trabalho. O ODSLab é um laboratório criado para responder aos desafios de desenvolvimento sustentável, os quais exigem novas formas de organização do trabalho (integrado, colaborativo e multidisciplinar) e modelos de governança ágil (AGENDA PÚBLICA, 2019).

O laboratório parte dos Objetivos de Desenvolvimento Sustentável (ODS), desenvolvidos pela Organização das Nações Unidas (ONU), para análises de problemas complexos (wicked problems), de 
modo que a interdependência entre dimensões sociais, econômicas e ambientais da realidade possa ser evidenciada e percebida objetivamente e que soluções práticas possam ser construídas em perspectiva interdisciplinar e intersetorial, reconhecendo não só dados objetivos, mas também as diferentes narrativas sobre o problema e possibilidades de solução.

No ODSLab, lideranças e representantes de diferentes setores e áreas se sentam à mesa para construir caminhos, alternativas e parcerias para enfrentar situações reais de alta complexidade relacionadas a problemas públicos. O diálogo e a produção de pactos e consensos são alimentados como forma de destravar impasses e mediar conflitos, sempre com base em diagnósticos aprofundados, dados e evidências. A metodologia induz a construção de agendas com ações de impacto rápido (quick wins), além de análises de práticas já testadas em outras localidades e experiências de usuários reais como forma de ampliar os repertórios de solução. Entre seus principais resultados estão a criação de instrumentos de fomento à agricultura, a instalação de áreas industriais e de um polo educacional no Pará, a criação de mecanismos de desenvolvimento regional no Piauí, a padronização e a integração de processos e a reabertura de um centro de atendimento a imigrantes e refugiados no estado de São Paulo (OSDLAB, 2019).

Uma segunda referência concebida a partir dos pressupostos de impacto coletivo é o programa Territórios Sustentáveis, implantado desde 2016 na região oeste do Pará, entre os municípios de Oriximiná, Faro e Terra Santa, próximos à Santarém (TERRITÓRIOS SUSTENTÁVEIS, 2019). Essa gigantesca e megadiversa região, com mais de 12 milhões de hectares (do tamanho de um país como Portugal), abriga áreas de proteção estaduais e federais e cerca de 88 mil pessoas distribuídas entre distintas populações tradicionais indígenas e quilombolas e núcleos populacionais dispersos em um território rico em florestas, cortado por grandes rios. Vem recebendo investimentos públicos e privados muito significativos destinados à construção de usinas hidrelétricas, pavimentação de estradas, abertura de terminais portuários e projetos de mineração, o que deve provocar forte pressão sobre a infraestrutura de serviços públicos e meios de vida da população, trazendo também oportunidades.

O arranjo do programa Territórios Sustentáveis prevê quatro frentes, que inclui fortalecimento da gestão pública, qualificação dos espaços de participação social (capital social), dinamismo econômico baseado na bioeconomia, alternativas de desenvolvimento para populações tradicionais e suporte às políticas ambientais. Com o objetivo de promover o desenvolvimento sustentável da região com foco na melhoria das condições de vida da população, a iniciativa é resultado da cooperação entre Agenda Pública, Ecam, Imazom, com apoio financeiro da Mineração Rio do Norte e coinvestimentos da United States Agency for International Development (USAID).

Com horizonte de atuação de 15 anos e ciclos bianuais de planejamento dos impactos coletivos, o programa Territórios Sustentáveis conta com organização de suporte responsável pela secretaria executiva (backbone organization), modelo de governança que prevê a participação dos atores regionais, incluindo também padrões de conduta e compliance, além de monitoramento de metas e indicadores comuns empregando um painel de acompanhamento (dashboard) construído especialmente para o programa. Os principais resultados do programa compilados até junho de 2019 incluem: o aumento da arrecadação em cerca de $11 \%$ no município de Oriximiná; a criação de um inédito fundo de desenvolvimento das populações quilombolas da região do Trombetas e implantação de seus mecanismos de governança; a construção de planos diretores nos três municípios; e a atração de mais de R\$ 2 milhões em recursos ligados à concessão florestal para a região. 


\section{SOLUÇÕES VIÃVEIS PARA UM MUNDO CADA VEZ MAIS COMPLEXO}

Qualquer um de nós que têm relação mais direta com a administração pública percebeu o quanto as dificuldades para implementar políticas cresceram no período mais recente. São dificuldades políticas e, principalmente, financeiras. Há forte pressão sobre os orçamentos, é verdade. Os investimentos públicos estão no menor patamar dos últimos 50 anos e os repasses federais aos municípios caíram acentuadamente (ALVARENGA, 2019).

Dentro dos governos, áreas têm competido pelo reconhecimento de que são prioritárias e, portanto, mais merecedoras de recursos ou da sua manutenção. Com isso, a cooperação também é afetada. As condições são ainda mais difíceis em estados com elevado endividamento como Rio de Janeiro, Minas Gerais e Rio Grande do Sul, só para citar os principais (GLOBO, 2019). Municípios ali situados padecem com atrasos ou simplesmente amargam a falta de repasses estaduais. A realidade financeira tem impacto direto na oferta de serviços. Menos dinheiro, menos serviços, menos bem-estar, mais problemas e insatisfação, menor coesão social. Portanto, é preciso combinar e otimizar recursos e o impacto coletivo pode trazer ganhos de eficiência mensuráveis.

Como vimos, não bastasse o argumento financeiro para motivar o envolvimento do ISP em arranjos de cooperação multiatores, a experiência de tratamento para problemas complexos demonstra a importância da combinação de esforços no gerenciamento desses desafios. Embora haja resistência ou mesmo certo desânimo por parte de alguns diante das dificuldades enfrentadas, circunstâncias ou resultados dos esforços conjuntos, o caminho é inescapável: é preciso agir em sinergia. Por isso, experiências que busquem mostrar caminhos e possibilidades são tão mais importantes agora.

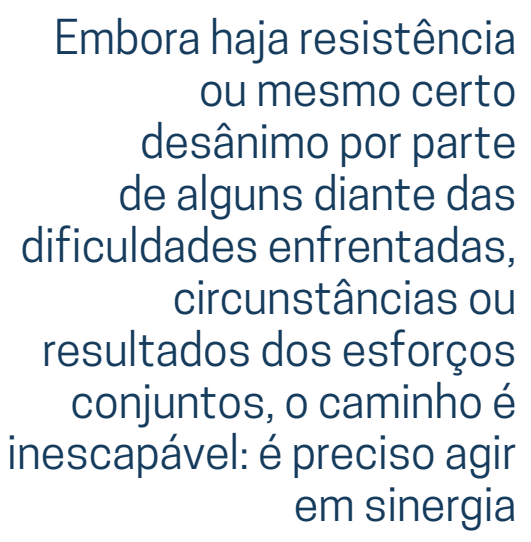

Olhando para a efetividade de nossas instituições públicas, apesar dos nossos visíveis fracassos, contamos uma história com alguns sucessos. Desde os anos 1940, o Brasil se desenvolveu, criou mercado interno, estabilizou a economia, fez surgir grandes empresas globais, combateu a pobreza, desenvolveu uma matriz energética limpa e chegou ao posto de oitava economia do planeta. Alguns poderão dizer que, "apesar de tudo", prosperamos em alguns aspectos, mantendo boa parte da nossa desigualdade estrutural, é verdade.

Porém, os desafios à frente são enormes e se fazem mais complexos. Mudanças estruturais na economia, com a reorganização internacional das cadeias de suprimentos, fluxos de capitais, desenvolvimento e combinação de novas tecnologias e mudanças profundas no fator trabalho. Política, religião, tecnologia, crise climática, migrações e refúgio. O mundo não é mais o mesmo e precisaremos também de inovações políticas, sociais e institucionais. Muitas delas estão nascendo em nível local. Precisamos agir rápido, pois as mudanças se aceleram e a proposta de constituir arranjos flexíveis, com atuação orgânica e governança ágil é uma das possibilidades de abordagem de impacto coletivo.

Há uma piada bastante difundida entre aqueles que pensam e vivem próximos à administração governamental. Quando um problema surge na agenda pública, os governos dão cabo dele criando um departamento. Com isso, mais uma vez, fragmentam iniciativas, dispersam energias e recursos. Não podemos dividir esforços. Não é a solução que encontra seu problema. É hora de promover impacto coletivo. Vamos juntos nessa? 


\section{REFERÊNCIAS}

ACEMOGLU, D.; ROBINSON, J. Por que as nações fracassam: as origens do poder, da prosperidade e da pobreza. Rio de Janeiro: Elsevier, 2012.

AGENDA PÚBLICA. ODSlab: soluções para problemas complexos. São Paulo, 2019. Disponível em: https://agendapublica. us16.list-manage.com/subscribe?u=091bbee55d2af3ed430a3705e\&id=4af045a340. Acesso em: set. 2019.

ALVARENGA, D. Taxa de investimentos é a menor em mais de $\mathbf{5 0}$ anos e fica mais dependente do setor privado. Portal G1, 19/07/2019. Disponível em: https://g1.globo.com/economia/noticia/2019/07/19/taxa-de-investimentos-e-a-menor-emmais-de-50-anos-e-fica-mais-dependente-do-setor-privado.ghtml. Acesso em: set. 2019.

ANDRADE, S. R. A difícil arte da mudança: construindo estratégias para gerar transformações sociais em parceria com o setor público. Censo Gife 2016. Disponível em: https://g1.globo.com/economia/noticia/2019/07/19/taxa-de-investimentose-a-menor-em-mais-de-50-anos-e-fica-mais-dependente-do-setor-privado.ghtml. Acesso em: set. 2019

ANDRADE, S. R.; SILVA, A. L. O alinhamento do investimento social privado às políticas públicas: Censo Gife 2014. Disponível em: https://gife.org.br/o-alinhamento-do-investimento-social-privado-as-politicas-publicas/. Acesso em: set. 2019.

BRESSER-PEREIRA, L. C. A reforma gerencial do Estado de 1995. Revista de Administração Pública, n. 34, v. 4, julho 2000, p. 55-72.

BROWN, V. A.; Harris, J. A.; Russell, J. Y. Tackling wicked problems through the transdisciplinary imagination. Londres: Earthscan, 2010.

CAVALCANTE, P. Inovação e políticas públicas: superando o mito da ideia. Brasília: IPEA, 2019.

CAVALCANTE, P.; CAMÕES, M.; CUNHA, B.; SEVERO, W. (orgs.). Inovação no setor público: teoria, tendências e casos no Brasil. Brasília: ENAP/ENAP, 2017.

CIF - Collective Impact Forum. What is collective impact. Disponível em: https://www.collectiveimpactforum.org/whatcollective-impact. Acesso em: set. 2019.

DASSEN, Nicolás. El peor trámite de mi vida. Gobernarte, 25 set. 2015. Disponível em: https://blogs.iadb.org/ administracion-publica/es/el-peor-tramite-de-mi-vida/. Acesso em: set. 2019.

EVANS, P. O Estado como problema e solução. Lua Nova, Revista de Cultura e Política, n. 28-29, 1993, p.107-156.

GIFE. Censo Gife 2016. Disponível em https://sinapse.gife.org.br/download/censo-gife-2016. Acesso em: set. 2019.

GLOBO. O endividamento dos estados e municípios. Infográficos [conteúdo exclusivo para assinantes]. Disponível em: https://infograficos.oglobo.globo.com/economia/o-endividamento-dos-estados-e-municipios.html. Acesso em: set. 2019.

HANLEYBROWN, F.; KANIA, J.; KRAMER, M. Channeling change: making collective impact work. Stanford Social Innovation Review, 2012. Disponível em: https://ssir.org/articles/entry/channeling_change_making_collective_impact_ work\#. Acesso em: set. 2019.

INOVA - Departamento de Modernização de Serviços Públicos e Inovação. Pesquisa de gestão da qualidade em serviços públicos federais: resultados preliminares. Arquivo em pdf. Disponível em: http://www.planejamento.gov.br/cidadaniadigital/brasil-eficiente-cidadania-digital/pesquisa-de-gestao-da-qualidade-em-servicos-publicos. Acesso em: set. 2019.

NORTH, Douglass. Instituições, mudança institucional e desempenho econômico. São Paulo: Três Estrelas, 2018.

OSDLAB. Uma nova gramática de colaboração para atingir os Objetivos de Desenvolvimento Sustentável. Disponível em: http://www.odslab.org.br/. Acesso em: set. 2019.

ROSETH, B.; REYES, A.; FARIAS, P.; PORRÚA, M.; VILLALBA, H.; ACEVEDO, S.; PEÑA, N.; ESTEVEZ, E.; LINARES LEJARRAGA, S.; FILLOTRANI, P. El fin del trámite eterno: ciudadanos burocracia y gobierno digital. BID, 2018. Disponível em https://publications.iadb.org/es/el-fin-del-tramite-eterno-ciudadanos-burocracia-y-gobierno-digital. Acesso em: set. 2019.

RUTHERFORD, M. Institutions in economics: the old and the new institutionalism. Cambridge: Cambridge University Press, 1994.

TERRITÓRIOS SUSTENTÁVEIS. Programa Territórios Sustentáveis. Disponível em: http://www.territoriossustentaveis. org.br/. Acesso em: set. 2019. 


\section{O AUTOR}

\section{Sergio Andrade}

Sergio Andrade é diretor-executivo da Agenda Pública. Mestre em Gestão e Políticas Públicas (FGV/EAESP), cientista social pela USP, especialista em Negociações Internacionais pela UNESP. Tem mais de 15 anos de experiência na área governamental e no setor privado, com trabalhos para diversos órgãos federais, estaduais e municipais. Recebeu prêmios de empreendedorismo social da Folha de São Paulo e do Fórum Econômico Mundial. 


\title{
artigos GIFE
}

Supervisão: José Marcelo Zacchi e Gustavo Bernardino

Coordenação: Graziela Santiago

Produção editorial: Gleice Regina Guerra

Apoio: Carolina Magosso

Diagramação: Clarissa Sitó

Impressão: Forma Certa

ISSN: 2674-8061

DOI: doi.org/10.33816/gife.20190102a3

(C) 2019 GIFE - Grupo de Institutos Fundações e Empresas

\section{(C) (i) ()}

Este material é disponibilizado sob a licenca Creative Commons Atribuição Não Comercial 4.0 Internacional. http://creativecommons.org/licenses/by-nc/4.0

As opiniões e análises expressas nesta publicação não necessariamente refletem as do GIFE.

\author{
Apoio institucional \\ Fundação Ford \\ Fundação Lemann \\ Instituto C\&A \\ Instituto Unibanco
}

QGIFE 